\title{
Acercamiento a la indumentaria y otras modas dieciochescas en boga en la clausura gaditana de Santa María del Arrabal
}

\author{
Frédérique Morand \\ Instituto de la Mujer de Alcalá de Henares
}

Resumen

Este artículo desvela parte de la situación vivida a diario por la comunidad de Conceptionistas calzadas de Santa María de Cádiz en materia de indumentaria y otras modas en boga tanto en el siglo como en la clausura durante la segunda mitad del siglo XVIII. A partir de la constatación de la persecución femenina por parte de los poderes públicos españoles con el fin de erradicar el pernicioso fenómeno en el siglo y, al contrario de lo que se afirmaba en la prensa, descubrimos en el propio redil los mismos abusos, con más resistencia aún. El minucioso estudio de los géneros de moda llevado a cabo ofrece un amplio abanico de la indumentaria usada en esta clausura gaditana, en la que "una de las más relevantes poetisas españolas» profesó con treinta y cinco años, tras ser madre y con la licencia de su esposo: sor María Gertrudis de la Cruz Hore (1742-1801), hija de pudientes comerciantes irlandeses y esposa de E. Fleming.

La presencia de seglares y el tipo de organización (la «vida privada» en oposición a la «vida común») permitían a las religiosas de Santa María estar al corriente de las costumbres de sus coetáneos así como vulnerar, a lo largo de la centuria, la autoridad de sus superiores sin temor alguna a las represalias. Verdadero lugar de reencuentro entre dos sociedades en apariencia opuestas, constatamos la proximidad de costumbre entre «las de fuera» (seglar) y «las de dentro» (reglar) a finales del Antiguo Régimen en Cádiz. Para realizar este estudio las fuentes utilizadas fueron documentos de índole religiosa y de carácter interno (mandatos de visitas, informes de elección de la abadesa y cartas de religiosas a sus confesores).

Palabras clave:

Monjas, Monasterio, Moda, Cádiz.

CES.XVIII, núm. 14 (2004), págs. 157-178. 


\section{La culpa es femenina ${ }^{1}$}

A lo largo del siglo XVIII el lujo y con él la vanidad invadieron buena parte de la sociedad española, y casi toda la europea. Aunque las modas parecen no tener otro origen que el capricho y la fantasía se pueden analizar desde otro punto de vista. El lujo está íntimamente ligado al progreso económico de una nación y a su comercio, es el vehículo financiero de parte de la industria de un país a la vez que resulta peligroso para las costumbres y la moralidad. La ciudad de Cádiz, lugar idóneo para este estudio, favoreció el flujo de divisas gracias al prolífero comercio con América, sobre todo a partir del 12 de marzo de 1717, fecha en la que la Corona decide transferir el Consulado y la Cámara de Comercio de Sevilla a Cádiz² . Sin embargo, la economía textil española, a mediados de siglo, sufrió enormes pérdidas: ciento cincuenta millones de libras se esfumaban cada año en el extranjero. La necesidad de introducción de ese dinero en las arcas del Estado español hizo preciso desarrollar la industria nacional ${ }^{3}$. Para ello, las mujeres eran el principal motor capaz de fomentar el cambio de costumbres; parecían las únicas capaces de salvar la economía del país de esa situación catastrófica y, paradójicamente, parecían las únicas culpables:

Más estima salir a la calle a parecer, lo que no es, que el que su Marido vaya ahorrando para poner su tienda [...]; poco la importa, que se adeude con el Casero, Criados y Menestrales; más insufrible se hace si la faltan las modas que llegan embarcadas en el capricho de algún Extranjero ${ }^{4}$.

Es harto sabida la intención de Floridablanca cuando escribió a la Junta de Damas de Honor y Mérito (el 16 de junio de 1788), informándoles de su deseo de establecer (con carácter obligatorio) un vestido femenino nacional. Con esta

${ }^{1}$ «El lujo es considerado la pasión femenina más común y dominante, porque «un exterior brillante» es el camino que siguen las integrantes de este sexo para ganarse el respeto del mundo, incapaces como son de acciones heroicas». Rosa María Capel Martínez, «Venturas y desventuras del matrimonio a los ojos de un clérigo ilustrado», Cuadernos de Historia Moderna, núm. 19, 1997, pág. 54.

2 Adolfo Castro, Memoria histórica de la población y de la estadística en la provincia de Cádiz escrita por acuerdo de la junta del censo de 1860, Cádiz, Imprenta y Litografía de la Revista Médica, 1862, págs. 13-18. Antonia Heredia Herrera, «Apuntes para la historia del Consulado de la Universidad de Cargadores a Indias en Sevilla y Cádiz», Anuario de Estudios Americanos, núm. 27, 1970, págs. 219-279.

${ }^{3}$ Paula Demerson, María Francisca de Paula Portocarrero, Condesa de Montijo, una figura de la Ilustración, Madrid, ed. Nacional San Agustín 5, 1975, págs. 155-156.

${ }^{4}$ José Isidro Cavaza, Conversación política sobre el lujo, daños que causa al Estado, modo que ha tenido de entronizarse y medios de atajarle, Madrid, José Doblado, 1786, págs. 9-10. 
idea pretendía apoyar la lucha contra el despilfarro considerado entonces como un grave defecto nacional ${ }^{5}$.

Puede extrañarnos la proposición de Floridablanca si tenemos en cuenta que en la década de los setenta Jovellanos, y otros de sus compañeros, expresaron sus votos particulares acerca de la introducción y el uso de las muselinas:

Que hablando particularmente de las mantillas, era constante que las de [...] muselinas, eran de fábrica extranjera, y que nadie podía asegurar si, desterradas éstas, se llevarán mantillas de fábrica nacional, [...]. Y que si para evitar este mal se quisiese obligar a las mujeres a usar solamente de mantillas labradas en España, se tropezaría en nuevos y mayores inconvenientes, y al cabo nada se lograría ${ }^{6}$.

Jovellanos afirmaba que, en este punto «era preciso haberse a las manos con las mujeres; esto es, con la clase más apegada a sus usos, más caprichosa, más mal avenida y difícil de ser gobernada» ${ }^{7}$. E insistía en el carácter poco resignado de las mujeres:

Que si esto sucedió con las leyes suntuarias, que hablaban derechamente con los hombres, ¿̨cuánto más sucederá con aquéllas que se dirigen a las mujeres, aun cuando el Gobierno quisiese entenderse para su ejecución con los padres y maridos, puesto que su condescendencia para las transgresiones tendría tantas disculpas cuantos caprichos y liviandades autoriza la moda y la debilidad del otro sexo? ${ }^{8}$

Al contrario de lo que sucedía en otros países como Francia o Rusia, los políticos españoles intentaron reformar sólo el lujo de las mujeres. No fueron los únicos en querer controlar la libertad de indumentaria, intentando influir en la construcción de identidades sociales. No obstante, la existencia de la moda era el índice de que las estructuras jerárquicas del Antiguo Régimen no eran

\footnotetext{
${ }^{5}$ Este proyecto (Discurso sobre el Lujo y proyecto de un traje nacional) fue dirigido por «mano anónima» a Floridablanca unos meses antes. El autor madrileño que firmaba M.O. decía ser una mujer y profesar vivos sentimientos patrióticos. Según P. Demerson, fue un marino de formación castrense y, al parecer, miembro de la Sociedad Matritense o sea, Martín Fernández de Navarrete. Para F. Aguilar Piñal fue obra del periodista Nifo. Paula Demerson, op. cit., págs. 163 y 164, n. 47. V. Manuel Antonio Ramírez y Góngora, Respuesta a las objeciones que se han hecho contra el proyecto de un traje nacional para las damas, Madrid, Imprenta Real, 1788. Carmen Carracedo FALAGÁn, «La regulación jurídica de la indumentaria femenina en Castilla durante la Edad Moderna», Revista Jurídica de Asturias, núm. 15, 1992, págs. 57-76.

${ }^{6}$ Gaspar Melchor de JovelLanos, «Voto particular del autor, sobre permitir la introducción y el uso de muselinas, al cual unieron el suyo otros miembros de la Junta de Comercio y Moneda», Obras, B.A.E., t. 50, vol. II, Madrid, Atlas, 1952, pág. 48.

${ }^{7}$ Gaspar M. de Jovellanos, art. cit., pág. 47.

${ }^{8}$ Ibídem, pág. 48.
} 
del todo inflexibles, aun permitían «cierto grado de movilidad social», en palabras de Mónica Bolufer?

Tras apoyarse en elementos históricos propios de la centuria y según la opinión de Michel Foucault cuando reflexionó sobre la tarea del historiador y se preguntó si había de renunciar al apoyo, aun de forma provisoria, de unidades literarias, si había de olvidarlas, renegándolas a meras ilusiones sin legitimidad alguna, pensé que lo más acertado sería sacar provecho de la unidad periodística $^{10}$.

Testigo privilegiado de la sociedad dieciochesca, ojeamos la prensa y más particularmente El Semanario erudito y curioso de Salamanca, muy instructivo en cuanto a la información hallada sobre las numerosas costumbres, ideas o prejuicios de la sociedad española de finales del setecientos:

Ya sabéis lo que pecáis

Y que esas modas os llevan

A penar eternamente

Si no hay contricción y enmiende ${ }^{11}$.

Está claro: la lírica ilustrada también intentó combatir el excesivo «despilfarro femenino». Las mujeres de la urbe se parecían al centro de la diana, siempre eran acusadas de ser las responsables de los males que achacaban el país. Prueba de ello, la teníamos en este mismo periódico, algo más tarde, donde otro poeta hacía una clara distinción entre seglares y religiosas:

$$
\begin{aligned}
& \text { También hay doncellas puras } \\
& \text { Hay las santas y perfectas } \\
& \text { Estas viven en los claustros } \\
& \text { Y aquellas en las ciudades }{ }^{12} \text {. }
\end{aligned}
$$

Al leer esta última estrofa publicada en el Seminario en 1797, en la que se critica la vanidad, la moda y los caprichos de las mujeres de las ciudades, sentí la necesidad de reunir parte del estudio conventual de la comunidad de

\footnotetext{
${ }^{9}$ Mónica Bolufer Peruga, Mujeres e ilustración: la construccción de la feminidad en la Ilustración española, Valencia, ed. Alfonso el Magnánimo, 1998, págs. 172-178.

10 «Il ne faut pas renvoyer le discours à la lointaine présence de l'origine; il faut le traiter dans le jeu de son instance.» Michel Foucault, L'archéologie du savoir, París, ed. Gallimard, 1969, pág. 37.

${ }^{11}$ Seminario Erudito y Curioso de Salamanca, t. XVII, núm. 483, el 31 de octubre de 1797. Extractos seleccionados por Fernando R. DE LA FLoR, El seminario erudito y curioso de Salamanca (1793-1798), Salamanca, ed. de la Diputación de Salamanca, 1988.

${ }^{12}$ S.E.C.S., núm. 487, el 18 de noviembre de 1797. Ibídem.
} 
Concepcionistas calzadas de Santa María de Cádiz; la necesidad de centrarme en el género femenino perteneciente a la sociedad eclesiástica de final del Antiguo Régimen porque, en este poético discurso, las monjas eran calificadas de mujeres ejemplares.

\section{La indumentaria de moda en el recinto sagrado}

Primero, podríamos preguntarnos qué papel desempeñó la indumentaria para las que formaron parte no del clero (como se confunde a veces), ya que las monjas nunca participaron del orden sacro ni de la jurisdicción eclesiástica, sino de las órdenes segundas ofemeninas, es decir, para las religiosas de clausura (las órdenes terceras eran seglares).

Desde los tiempos más remotos, las comunidades establecidas en las ciudades recibieron el hábito de sus fundadores; este vestido uniforme marca la orden en la que profesaron. Así, desde la fundación de su monasterio, el 14 de mayo de 1527, las hermanas Concepcionistas calzadas de Cádiz vestían el hábito de Beatriz de Silva, fundadora de la orden en Toledo el 30 de abril de $1489^{13}$. Y, según la definición recogida en la Enciclopedia, en la acepción «hábito religioso» podemos leer: «las órdenes religiosas no pudieron cambiar como los laicos, tampoco seguir las modas que el tiempo hizo brotar ${ }^{14}$. Adentrémonos en el universo conventual para averiguar en qué consistía aquella sencilla definición. En primer lugar, hace falta recordar que en este monasterio de Santa María no vivían sólo esposas de Dios, sino también mujeres cuyo estatuto no era el de religiosa: había sirvientas, criadas, lavanderas, viudas alquilando una celda, mujeres nobles o de la alta sociedad en trámite con la justicia, o recluidas por malos tratos, niñas cuyos padres se habían ido de viaje sin saber donde dejarlas, o simplemente niñas huérfanas o educandas y, no podemos olvidar que a veces, en la clausura, también había esclavas ${ }^{15}$.

${ }^{13}$ Dentro de la familia Franciscana, a la que pertenece la Orden Concepcionista, existen tres «tipos» de monjas: las clarisas, las recoletas y las terciarias (las de Santa María). Juan Sáez Marín, Datos sobre la Iglesia Española (1768-1868), Madrid, ed. Nacional San Agustín 5, 1975, pág. 237. V. el excelente artículo de Ángela Muñoz Fernández, «El monacato como espacio de cultura femenina. A propósito de la Inmaculada Concepción de María y la representación de la sexuación femenina», Pautas históricas de sociabilidad femenina, rituales y modelos de representación, Actas del V Coloquio Internacional de la Asociación Española de Investigación Histórica de las Mujeres, Universidad de Cádiz, eds. Mary Nash, M. José de la Pascua, Gloria Espigado, 1999, págs. 71-89.

${ }^{14}$ Diderot y D'Alembert (eds.), Encyclopédie, ou dictionnaire raisonné des sciences, des arts et des métiers (1751-1771), t. VIII, Paris, Librairie Le Breton, pág. 16.

${ }^{15}$ Localicé la partida de bautismo de María Manuela Josefa de la Encarnacíon, negra natural de Calavarí (Costa de Guinea) de trece años. Fue esclava de la abadesa Manuela Fernández en 1774. Sin 
Es fácil imaginar, aquella mezcla, a menudo conflictiva, provocó numerosas discordias en el convento a lo largo del siglo XVIII. Por ello, la abadesa y el discretorio debían manifestar su acuerdo, así como obtener la autorización escrita de su superior, para que aquellas mujeres entrasen en el convento. Por lo visto, en Santa María no había otro lugar dónde recibirlas ${ }^{16}$.

Analicemos la situación a partir de documentos de índole religioso como lo son los mandatos de visitas, los informes de elección de la abadesa, o las cartas de algunas de las religiosas a sus confesores. Difícilmente podríamos poner en tela de juicio aquellas informaciones de carácter interno. En este caso, las actas recopiladas lo fueron bajo las órdenes de don Miguel Benito Ortega, Canónigo Penitenciario de la Iglesia gaditana y visitador de los conventos de religiosas de la diócesis. Tenemos constancia, en 1750, de una queja dirigida a las seglares que moraban en el convento.

En teoría, eran sometidas a una disciplina. Sin embargo, los superiores eclesiásticos hicieron constar que la amonestación se dirigió a la comunidad con anterioridad sin que nadie pareciese dispuesto a remediarlo ${ }^{17}$ :

Varias veces hemos mandado, y providenciado sobre trajes de seglares, y sobre la distinción que debe haber entre las que legítimamente son recibidas por tales, y las que sólo entran de sirvientas, [...] pero queriendo siempre competir con el traje de verdaderas seglares, no debiéndolo ser ni aun en la apariencia; y es sin igual nuestro dolor, en ver que poco o nada se ejecuta de cuanto está mandado en

\footnotetext{
embargo, el clero prefirió atribuirla a una simple religiosa, encubriendo su presencia al servicio de la priora. A.P.S.C., Libro de Bautismo (1773/1774), libro 72, ff. 154-155. Margarita Ortega López hace referencia al mundo de las seglares, a las que pasaban en un convento para ser educadas, a las que se quedaban luego como seglar y a la disparidad de clases, aun en un mismo recinto. Por tanto, y con razón, destaca cierta dificultad de convivencia en el recinto. Margarita Ortega López, «Casa o convento, la educación de la mujer en las edades moderna y contemporánea», Historia 16, núm. 145, Madrid, mayo 1988, págs. 41-48. M. ${ }^{a}$ Leticia SÁnChez HernÁndEz, «Las variedades de la experiencia religiosa en las monjas de los siglos XVI y XVII», Revista Arenal, (coords.) Margarita Ortega y M. ${ }^{a}$ Victoria López Cordón, «La religiosidad de las mujeres», Instituto de la Mujer, Universidad de Granada, vol. 5, núm. 1, enerojunio 1998, pág. 70.

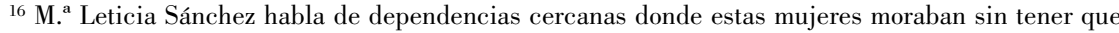
respetar una estricta clausura; descubrimos otra forma de organización conventual. M. ${ }^{a}$ Leticia SÁNCHEz HERNÁNDEZ, art. cit., págs. 79-80.

${ }^{17}$ Existía unas normas establecidas para las seglares en la clausura: Constituciones generales para todos los Colegios de doncellas seglares, que están en los Conventos de la orden de nuestro Padre San Francisco. Hechas y aprobadas en el sobredicho Capítulo General de Roma del año 1639. Al igual se establecieron pautas de conducta para las religiosas: Constituciones generales para todas las monjas y Religiosas, sujetas a la obediencia de la Orden de nuestro Padre San Francisco en toda la familia Cismontana. De nuevo recopiladas de las antiguas. Y añadidas con acuerdo, consentimiento y aprobación del Capítulo General celebrado en Roma a once de junio de1639, Madrid, 1748. Citado por J.L. SÁnchez Lora, Mujeres, conventos y formas de la religiosidad barroca, Madrid, Fundación Universitaria Española, 1988, págs. 233-234.
} 
esta línea. Por lo cual, reiterando aquellos preceptos prohibimos con todo rigor el uso de zapatos de colores, galones, puntas, o franjas ${ }^{18}$.

Pese al elogio poético publicado en el Semanario, en la comunidad de religiosas concepcionistas de Santa María los abusos cometidos revelan estar directamente relacionados con la indumentaria; se convierte en una situación que afecta tanto al comportamiento de las seglares como al de algunas de las religiosas y, contra todo pronóstico, el porte del hábito profano, las modas y los atavíos invadieron también el universo de la clausura.

Ya empiezan a aparecer en las listas algunas prendas de moda en la clausura gaditana: zapatos de colores, galones, puntas y franjas. Acerquémonos a los géneros que se llevaban en Santa María. El visitador no da precisión alguna sobre los tipos de zapatos usados y tampoco sobre los colores, pero sabemos, según los dichos de algunos viajeros extranjeros, que las españolas tenían particular cuidado en el calzado ${ }^{19}$. La moda en Europa, y por supuesto en Cádiz, ciudad portuaria y cosmopolita, consistía en disminuir lo más posible el pie, usando para ello calzado estrecho que impedía el andar cómodo y aun su crecimiento natural. Antonio Alcalá Galiano confirmó aquella práctica en las costumbres de las gaditanas y añadió que solían llevar zapatos cortos y bajos ${ }^{20}$. Los zapatos fueron, desde los tiempos más remotos, signos de distinción y compañeros del lujo. En la Antigüedad se solían adornar de perlas y bordados; el color «honesto» de los zapatos de las mujeres era el blanco. En la civilización romana una mujer honesta no se atrevía a llevar zapatos rojos, era el color de las cortesanas. En el siglo dieciocho ya era costumbre, aun para mujeres discretas, llevar el calzado de color, hermoseado con algunos adornos, lo que los padres de la Iglesia miraban como una verdadera invención del diablo ${ }^{21}$. Así pues, en la clausura también se llevaban zapatos de colores.

El origen de los galones, a los que el superior hacía alusión, se halla en las piezas que se ponían en los vestidos desgastados para tapar agujeros y manchas. Después de haber sido un signo de pobreza se volvieron el hermoseo y ornato de los ricos. Eran estrechos tejidos que se fabricaban con oro, plata,

\footnotetext{
${ }^{18}$ A.D.C, Sección I. Secretaría de Cámara. Visitas pastorales, leg. 507, f. 14. Una visita de 1750.

${ }^{19}$ Christian August Fischer, Voyage en Espagne aux années 1797 et 1798, trad. Ch. Fr. Cramer, Duchesne, París, Lériche, 1801, t. I, págs. 242-243. Citado por E. Fernández Herr, Les origines de l'Espagne romantique. Les récits de voyage 1755-1823, París, Didier, 1973, pág. 156.

${ }^{20}$ Antonio Alcalá Galiano, Recuerdos de un anciano, Madrid, lib. y casa ed. Hernando, 1927, págs. 11-12.

${ }^{21}$ Existía el zapato ligero llamado escarpín, y se hacía de dos formas: el escarpín «vuelta del revés» y escarpín «sin vuelta del revés». Encyclopédie, t. XV, págs. 404-406.
} 
seda o a veces con hilo sólo. También existían los de lana. Los galones de oro o de plata servían para adornar los vestidos de los pudientes. Se los llamaban «bordaduras», «bordados a canutillo», o «bordados de realce» según la forma del dibujo y según la indumentaria (sombrero o ropa).

Cuando el visitador mencionó el género de las puntas, según el Diccionario de la Real Academia, se refirió al «encaje que forma ondas o puntas en una de sus orillas.» Tal vez, se trate de este término de «Marchand de mode» llamado mouchoir-frise en francés, tipo "pañuelo friso o rizado», compuesto de tres rangos de gasas briscadas o pintadas, de blondas o de encajes, montados por estrato en una cinta de hilo bastante estrecho y plisado. Esta vestidura servía a las mujeres para ponerse en el cuello y podía medir de cuatro a cinco dedos de ancho por tres cuartos de largo ${ }^{22}$. Había franjas de oro, de plata, o de seda para adornar las faldas de las mujeres. Eran de alturas y materias muy distintas, se hacían de varios colores o de uno solo ${ }^{23}$. En este caso no conocemos las modalidades exactas que se llevaron en clausura puesto que los superiores eclesiásticos no se detuvieron en los pormenores de la indumentaria llevada por estas criaturas - hay que decirlo_- poco obedientes.

En la clausura el uso de la moda resultó el medio idóneo para existir. Transformándose en una entidad particular capaz de contrarrestar las normas establecidas, tanto las monjas como las seglares pretendieron «ser» a través de estas manifestaciones sociales asumiendo, en cierta manera, el total desacuerdo con la Regla de la institución.

Fueran religiosas, fueran seglares, la indumentaria fue un punto sobre el cual los visitadores tuvieron muy poca autoridad. Fue una cuestión sobre la que tuvieron que insistir a menudo, como subrayó Arturo García Morgado en sus distintos estudios ${ }^{24}$. Ni las seglares, ni parte de las religiosas parecían dispuestas a acatar tal restricción:

Y mandamos que por ningún motivo ni pretexto sea osada ninguna religiosa a usar el traje de cotilla, ni otro alguno que en la exterioridad haga afectación de pompa, ni en lo interior profane la modestia. [...] Pues ni con tanta inútil pésima,

${ }^{22}$ Encyclopédie, Suplemento, t. III, s.p.

${ }^{23}$ La franja estaba compuesta de tres partes: la cadeneta, la cabeza y el cuerpo. Cuando estaba en la parte inferior, se llamaba molleado, cuando la cabeza era larga y labrada de tal forma que dejaba pasar la luz y que los hilos eran más largos y más sueltos que las franjas normales, se llamaba crespín. Había también franjas de seda trenzada y otras cuya seda no estaba trenzada; estas últimas se llamaban franjas cortadas. Encyclopédie, t. VII, pág. 287.

${ }^{24}$ A. Morgado García, Iglesia y sociedad en el Cádiz del siglo XVIII, Cádiz, Universidad de Filosofía y Letras, 1989. Del mismo autor: «Los conventos de monjas concepcionistas en el Cádiz del siglo XVIII», La Orden Concepcionista, Actas del I Congreso Internacional, vol. 1, León, 8 al 12 de mayo de 1989, Monasterio de la Purísima Concepción, V Centenario (1489-1989), 1990, págs. 299-311. 
y vana ocupación de aderezarse, podrán salir jamás de vestir una mortaja, ni para con Dios serán con un hábito como de devoción, otra cosa, que unas indevotas mujeres, y Religiosas fingidas ${ }^{25}$.

Detengámonos un instante en este género de moda llevado por las propias monjas. Por «traje de cotilla» se entendía el corsé. Esta prenda interior estaba armada con ballenas para ceñirse al cuerpo debajo del pecho hasta las caderas. El jubón cubría desde los hombros hasta la cintura y se llevaba ceñido y ajustado al cuerpo, según las definiciones del Diccionario de la Real Academia Española.

No obstante, leyendo el artículo de M. le Chevalier de Jaucourt en la Enciclopedia, en la acepción corset, vemos que se trataba de una prenda de tela picada sin ballena que se ataba por delante con cordones planos o con cintas; las llevaban las mujeres en déshabillé. Esta prenda de vestir levantó numerosos debates, tanto entre los hombres preocupados por la economía del país así como entre los médicos, y pronto se escribieron tratados sobre las extrañas enfermedades que producía el uso de las cotillas ${ }^{26}$.

Se evidencia la laxitud de la Madre Abadesa, que tuvo sin duda parte de responsabilidad en el incumplimiento de las pautas conventuales en materia de indumentaria. Consciente del mayor rigor con el que la priora debía intentar que se respetase la Regla, el superior repitió sus advertencias no sólo para las que pronunciaron los votos, sino también para las que no pertenecían a la Iglesia:

Encargamos con el mayor cuidado a la Madre Abadesa no permita que ninguna seglar sea de la mejor calidad, y distinción, traiga, ni use de traje profano, ajeno a un claustro religioso: y de que las sirvientas no usen más distinción de vestido, y parte, que el que las corresponde a su estado ${ }^{27}$.

Mientras que erradicar la «profanidad» en el vestir de las feligresas se convertía en el objetivo de una serie de edictos y cartas pastorales, descubrimos, en el propio redil, abusos semejantes ${ }^{28}$.

${ }^{25}$ A.D.C., Visitas pastorales, leg. 507, f. 7. Una visita de 1740.

26 «deslizándose estos líquidos acres por la boca del útero, caen a la vagina, y salen por la vulva causando los estragos expresados, y conocidos con los nombres de flujos blancos y gonorreas simples: estas enfermedades siempre sospechosas han puesto en duda la conducta de algunas honradas pacientes con sus maridos, procediendo solamente del uso de las cotillas», Mariano Martínez Galinsoga, Demostración mecánica de las enfermedades que produce el uso de cotillas, Madrid, Imprenta Real, 1784, págs. 33-34. Felipe Rojo DE FLores, Invectiva contra el lujo, su profanidad y excesos por medio de propias reflexiones, que persuaden su inutilidad, Madrid, Imprenta Real, 1794, págs. 106-107.

${ }^{27}$ A.D.C, Visitas pastorales, leg. 507, ff. 7-8. Una visita de 1740.

${ }^{28}$ Existió una ley que especificaba claramente el deber de los eclesiásticos: «Se encarga a los Obispos y Prelados corrijan con celo y discreción las modas escandalosas de las mujeres, pidiendo auxilio 
Ahora bien, interesa resaltar que tanto las seglares «depositadas» ${ }^{29}$ como las que vivían en la clausura raramente entraban solas; acompañadas por sus criadas las cuales, deseando rivalizar o imitar a su dueña, no hacían más que acentuar el clima de libertad que ya había invadido el lugar ${ }^{30}$.

Desesperado por la mala conducta de esta comunidad de mujeres, el 28 de abril de 1776, el obispo escribió de nuevo a la Madre Abadesa proponiéndole (como hizo Floridablanca para remediar a tanto despilfarro e indisciplina) el porte de un traje común para todas las seglares en clausura:

Y para que así mejor se cumpla esto en cuanto al traje exhortamos a dichas seglares que usen, y vistan algún hábito de Dolores, Carmín, u otro de igual color, y les declaramos prohibidos absolutamente en el Convento Zapatos de color, o la Operanta, Gasas, Blondas, Mandiles, Guardapiés de otro color que el referido, o con farfalás, Cabriolés, Naguas de lienzo blanco con farfalás, o sin ellos u otra moda del mundo, y que desdiga de la modestia, y gravedad, que debe reinar, y respirar el Convento ${ }^{31}$.

A pesar de las constantes prohibiciones se seguía llevando en el interior de la clausura no sólo moda del siglo XVIII, sino también moda de épocas anteriores, como las gasas. Hechos de tejido ligero de hilo, o todo de seda, labrado de tal forma que dejaba pasar la luz, la fabricación de las gasas era «muy ingeniosa», según las reflexiones encontradas en el Dictionnaire du Commerce ${ }^{32}$. $\mathrm{Al}$ contrario, la blonda era un género típicamente dieciochesco. La acepción de esa palabra viene del francés blonde y tiene fecha de 1743. Es una obra de seda hecha de la misma forma que el encaje y a la que se parece. Existían dos géneros: la llamada «blonda labrada» y la «blonda de fantasía».

La blonda labrada difería sólo por la materia; el dibujo era selecto, la ejecución suave y formaba una pieza cuya hermosura inmortal se reconocía inde-

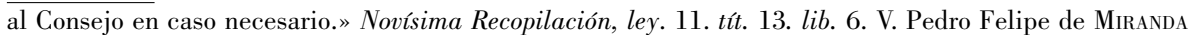
Ponce de León, Modestia, y honestidad en el Vestido, Odio, y Aversión a los Trajes profanos, s.l., s.a., s.p. Lucas Campoo y Otazu, Sermón contra el lujo y la profanidad en los vestidos y adornos de las mujeres cristianas, predicado en la iglesia catedral de la ciudad de Málaga el domingo quinto de Cuaresma del año de 1781, Madrid, Benito Cano, 1787. Citado por Mónica Bolufer Peruga, op. cit., págs. 181-182, n. 104.

${ }^{29}$ Eran mujeres que entraban en clausura de forma temporal por malos tratos, porque su familia salía de viaje y no sabía donde cobijarlas, por pleito de adulterio o desavenancias con sus padres, etc...

30 «Está también mandado en cuanto a las seglares, y sirvientas, que moran en el convento, que vistan de tal forma que se conozca la diferencia que debe haber entre unas, y otras, según su destino, y condición, y que todas vistan honestamente, sin zapatos de color, ni otra moda de siglo, como corresponde a un claustro religioso;» A.D.C, Visitas pastorales, leg. 507, f. 30. Una visita de 1776.

${ }^{31}$ Ibídem, ff. 36-37.

${ }^{32}$ Encyclopédie, t. VII, págs. 532-533. 
pendientemente del capricho y de las circunstancias, según afirmaron hombres del setecientos. La blonda labrada imitaba muy bien el encaje y era tan cara como estimada. Habitualmente, las blondas eran de un solo color, o sea blancas. Pese a ello, existían algunas mezclas de negro, rojo y otros colores para adornar las faldas de las damas. En general, las blondas de fantasía eran menos costosas estando más pendientes del capricho y de los gustos.

Conocemos algunas por el afán de conocimiento de los enciclopedistas: las llamadas berg-op-zoom eran blondas cuyo dibujo empezó a aparecer cuando la ciudad fue asaltada ${ }^{33}$, la «felpilla» era una blonda cuyo principal dibujo estaba rodeado de una brizna de felpilla, la «blonda perejil» estaba compuesta por una infinidad de pequeños cuadrillos, bastante parecidos a la figura de una hoja de perejil, la de «puntos a la reina» era una blonda que formaba varios cuadrillos llenos y vacíos. La llamada «pulgar del rey» era una blonda cuyo dibujo grande representaba un abanico abierto y roto desde abajo y por el medio. Las marchandes de modes las utilizaban mucho para engalanar sayas, preparar el peine, las pelucas, los puños, o las palatinas. Estas últimas son adornos de marta, seda, o pluma que se usaban para cubrir y abrigar la garganta y el pecho a modo de corbata ancha y tendida; se hacían de blonda, pero también de cinta, de encaje, de felpilla y otros tejidos.

En la época de la poetisa y monja erudita sor María Gertrudis de la Cruz Hore (1742-1801), hoy día considerada una de las más relevantes poetisas del siglo XVIII ${ }^{34}$, las blondas se ponían sobre una cinta de un dedo de ancho, formando varios pliegues ${ }^{35}$. Es indudable, algunos de los géneros de moda encontrados en el convento en el que la poetisa gaditana pasó los veintitrés últimos años de su existencia, poco tenían que ver con el santo hábito ${ }^{36}$.

Lo que mencionó el eclesiástico en cuarto lugar son los guardapiés. Eran vestidos de seda o de tela rica que bajaban hasta los pies. Los que se llevaban

\footnotetext{
${ }^{33}$ Se trata de una cuidad de los Países Bajos, Bergen op zoom, en el Brabante holandés con una parte en una montaña y otra en el río Zoom.

${ }^{34}$ Mónica Bolufer Peruga, «Escritura femenina y publicación en el siglo XVIII: de la expresión personal a la República de las letras», Género y ciudadanía. Revisiones desde el ámbito privado, Instituto Universitario de Estudios de la Mujer, XII Jornadas de investigación interdisciplinaria, eds. Margarita Ortega, Cristina Sánchez, Celia Valiente, Universidad Autónoma de Madrid, 1999, págs. 199-200.

${ }^{35}$ Encyclopédie, t. II, págs. 286-288; t. III, págs. 294-295 y t. XII, pág. 131.

${ }^{36}$ Esta misteriosa dama fue la única monja casada del cenobio. Entró con la licencia de su marido (él juró castidad y se quedó en el siglo) en 1778, con treinta y cinco años; murió el 9 de agosto de 1801 en su celda. V. Frédérique Morand, «Primer acercamiento a la poetisa y religiosa Doña María Gertrudis Hore (17421801): alias la «Hija del Sol», Cuadernos de Ilustración y Romanticismo. Revista del Grupo de Estudios del Siglo XVIII de la Universidad de Cádiz, (coord.) Romero Ferrer Alberto, núm. 10, 2002, págs. 171-184. De la misma autora: «¿Qué sabemos del hijo de la monja Sor María Gertrudis de la Cruz Hore (1742-1801) y de su esposo, Esteban Fleming?», Dieciocho, Universidad de Virginia, U.S.A. (en prensa).
} 
en la clausura eran de colores y con faralás, el nombre dado a las bandas de tafetán que se ataba a las sayas de las damas y cuyo número se ponía a discreción; había a veces dos, tres, cuatro o cinco. Cosidos sólo por la parte superior, el viento hacía volar la parte inferior. Había de distintos colores y estaban tan de moda que cada volante llegó a tener varios colores, según las explicaciones dadas por el incansable colaborador M. le Chevalier de Jaucourt ${ }^{37}$.

Se repitieron el uso de mangas de punta, franjas, cotillas y el uso más sencillo, aunque prohibido, de las enaguas de tela blanca con o sin volantes. En fin, todos estos enseres distorsionaban realmente el austero universo de la vida claustral, ese mundo "sin apenas contacto con el exterior». ${ }^{38}$ Es de suponer que el contraste entre los rigores conventuales y la tentadora proximidad de las seglares convertían la austeridad del hábito en un concepto todavía más difícil de respetar para las hermanas:

También hemos extrañado el uso de mangas de punta en el hábito de las religiosas siendo como es, contra su propia forma, y antigua observancia, y de mayor costo que necesitan ahorrar para otros menesteres, y así las prohibimos absolutamente desde ahora para siempre, y ordenamos que las que las tienen se las quiten, y no usen jamás, usando todas las que corresponden a su hábito según su institución ${ }^{39}$.

Interesa resaltar que no sólo los superiores, sino las propias hermanas, delatando a las suyas, fueron las que me facilitaron un mejor conocimiento del universo conventual en materia de indumentaria. Leamos a sor Gertrudis:

En punto al calzado hay altercaciones, las Antiguas dicen que colores honestos son azul, o verde; otras defienden que el color más honesto es el blanco, del que usan todas las Religiones, hay de uno y otro, pero como la Madre Abadesa las gasta blancas, pocas las llevan de color ${ }^{40}$.

${ }^{37}$ Encyclopédie, t. XVII, pág. 442.

${ }^{38}$ A. Morgado García, Iglesia y sociedad en el Cádiz del siglo XVIII, pág. 180.

${ }^{39}$ A.D.C, Visitas pastorales, leg. 507, f. 33. Una visita de 1776 . El hábito se compone de una túnica y de una saya con escapulario de color blanco. El manto ha de ser de tela basta o de estamiño, color jacinto. La longitud del hábito o de la túnica exterior ha de corresponder a la estatura exacta de la religiosa y la apertura de la manga no sobrepasará los cincuenta centímetros de ancho. Los zapatos de la orden franciscana suelen ser sandalias. La ropa interior puede ser ligera, pero lo más importante es que sea conforme a la pobreza y mortificación religiosa. Regla y constituciones generales de las monjas franciscanas de la orden de la Concepción de la B.V.M, ed. de la Provincia Franciscana de Cataluña, Barcelona, 1943, cap. III, § 140-142.

${ }^{40}$ A.D.C, Sección I. Despacho de los Obispos. Fray Antonio Martínez de la Plaza, leg. 45, s.n. Esta carta fue escrita a principios de 1796 por Sor María Gertrudis de la Cruz Hore y dirigida al obispo. 


\section{Lo invisible de las clausuras}

Podemos extrañarnos de la disonancia en el vestir de esta comunidad de religiosas, cuyo hábito habría de ser el mismo, o podríamos seguir la lista de abusos a lo largo de todo el siglo sin que los eclesiásticos fueran capaces de remediarlo. No obstante, para entender mejor esta situación algo inesperada, detengámonos en un matiz olvidado de la vida conventual:

La Vida Común [...] es la más acomodada al recogimiento, retiro espiritual, abstración de las criaturas de siglo, y al cumplimiento de los Santos ejercicios de supererogación y consejo; [...] Este es el sentir de los Maestros de espíritu [...] que han frecuentado los confesionarios de las Religiosas de una y otra clase de vida; y así por lo general se experimenta en las Descalzas, Franciscanas Recoletas, Capuchinas, Carmelitas, y en todas las Calzadas que tienen la Vida Común ${ }^{41}$.

Según las constituciones de cada monasterio, las religiosas vivían bajo el régimen de «vida privada y particular» o bajo el de «vida común». Existían varias clases de monjes (Hermitaño, Sarabaíta...), aunque los verdaderos eran los cenóbitas y los anacoretas, pero siempre ha habido un solo género de religiosas, el de las cenóbitas. Según nos enseña la lectura de una carta familiar escrita por el doctor Martín Carrascal, este nombre, «cenóbita», es lo mismo que decir «sujeto que guarda la vida común»; es una voz griega que se deriva de communis, que significa común, y de vita que quiere decir vida ${ }^{42}$ :

Por esto los Monasterios [...] en su riguroso sentido es la casa donde los que habitan tienen Vida Común. Monasterio es puntualmente el significado de Cenobio, o habitación de Cenóbitas; así lo dicen los Italianos: Convento de Frati, «dove si vive à Commune». En Castellano se lee: lugar donde se lleva la Vida Común ${ }^{43}$.

Vemos que el régimen de «vida particular» —más propenso en las congregaciones calzadas- está ya en total desacuerdo con los principios de una institución religiosa. Una situación que ocurría mucho después del concilio de Trento (1545-1563), aunque se dice que «desde la promulgación de la bula Circa Pastoralis en 1566» la clausura «se ha vuelto muy estricta» ${ }^{44}$.

\footnotetext{
${ }^{41}$ Martín Carrascal Rivera y Aparicio, Utilidades espirituales, y temporales de la vida común en monasterios de monjas, Madrid, Imprenta de Josef Doblado, 1780, págs. 62-63.

${ }^{42}$ Ibídem, págs. 50-53.

43 Ibid, págs. 55-57.

44 A. Domínguez Ortiz, Las Clases privilegiadas en la España del Antiguo Régimen, Madrid, Istmo, 2. ${ }^{a}$ ed. 1979, págs. 331 y sigs. Citado por Arturo Morgado García, «Modelos de comportamiento religioso en la
} 
Ahora bien, los cimientos de una fundación monástica, según la definición dada por la Enciclopedia, debía tener un número competente de religiosos, observar la regla del orden y tener o haber tenido «claustrum, arca communis \& sigillum», es decir lugares reglares (claustro, refectorio...), administración común y sello particular ${ }^{45}$. La comunidad de Santa María tuvo y sigue teniendo sello propio de la casa, así como lugares reglares, aunque no desde su fundación; el refectorio se mandó construir en 1701 sólo. En palabras del obispo:

encontré descrecida la observancia regular en la parte de no tener refectorio, he procurado por los medios más convenientes y suaves reducirlas a él y actualmente estoy dando planta para su erección y perpetuidad, habiéndoles destinado los medios competentes, por cuya falta se había tolerado este abuso, y darán principio a esta vida común dentro de muy pocos días, de que resultarán saludables efectos en su observancia ${ }^{46}$.

No obstante, hasta hace poco el monasterio no disfrutó de los fundamentos de la «vida común» o sea de la administración en común de los bienes, pese a que el mismo estatuto conventual obligaba a las monjas a tener arca communis a fin de que se repartiese las rentas de forma más equitativa.

Desde su fundación (el 14 de mayo de 1527), la congregación vivía bajo el régimen «de vida privada». Es decir, cada religiosa administraba su peculio y sus rentas de forma individual para subvenir a sus necesidades. Las monjas de Santa María no tenían la obligación de comer juntas en el refectorio sino que podían hacerlo en su celda, en presencia de su criada (y/o de su esclava) y con otra(s) religiosa(s) que compartía(n) la habitación; solían ser dos, tres o cuatro (como mucho) fuesen seglares o religiosas, de la misma familia o no, las que podían vivir en la misma celda. Esta organización les obligaba a comprarse el vestido, puesto que el convento no se encargaba de gastos particulares.

Finalmente, se precisaba un cambio radical en la comunidad de Santa María: el 23 de abril de 1796, y después de varios intentos desde principios de siglo, el obispo fray Antonio Martínez de la Plaza propuso, oficialmente, el establecimiento de «vida común».

\footnotetext{
España del siglo XVIII. El caso del convento de concepcionistas franciscanas descalzas de Nuestra Señora de la Piedad (Cádiz)», separata de Archivo ibero-americano, núms. 201-202, 1991, pág. 201.

${ }^{45}$ Encyclopédie, t. X, pág. 638.

${ }^{46}$ A.S.V., Sagrada Congregación del Concilio, Relationes, Cádiz, caja-legajo núm. 354: Visita ad limina de Alonso de Talavera, 11 de septiembre de 1701. Citado por Pablo Antón Solé, «La observancia de las monjas gaditanas en el siglo XVIII», VII Encuentro de la Ilustración al Romanticismo. Cádiz, América y Europa ante la modernidad. La mujer en los siglos XVIII y XIX, Cádiz 19, 20 y 21 de mayo de 1993, coord. Cinta Canterla, Universidad de Cádiz, 1993, pág. 141.
} 
Sin embargo, las monjas consiguieron, por lo menos en cuanto a la organización interna, ejercer cierto poder de decisión en su institución. Ellas impusieron su voluntad durante más de un siglo, ignorando las decisiones de sus superiores y obligándoles, por lo menos desde 1701, a aplazar sus voluntades: aun en noviembre de 1797, quince de las treinta y ocho monjas de Santa María se negaron rotundamente a adoptar los principios de «vida común» ${ }^{47}$.

Pero ¿cómo explicar la existencia, todavía a finales del siglo XVIII, de fundaciones de «vida privada»? Seguimos leyendo al vicario de Peñafiel, cuando, el 23 de junio de 1779, escribió a sus dos sobrinas, religiosas de «vida privada»:

¿cómo sufren los Prelados seculares y regulares, la vida privada y particular, los Peculios, Rentas y Vitalicios? Lo sufren, es verdad, pero con dolor en todos aquellos Conventos y Monasterios, que a la luz de la verdad (pero oscurecida, o que se quiere apagar con velos aparentes) podían seguir la Vida Común ${ }^{48}$.

El propio se ve espantado por tales costumbres totalmente opuestas a los preceptos básicos de la vida claustral pero, aparentemente, la Iglesia no tuvo la autoridad suficiente para detener estas «prácticas religiosas». Por tanto, en este monasterio de «vida privada», los géneros de moda fueron múltiples y variados.

María Gertrudis de la Cruz Hore hizo algunas compras que poco tenían que ver con el voto de pobreza: adquirió, desde la clausura, telas indias o, para ser más exactos, tres varas de telas pintadas de las Indias.

Detengámonos un momento en esta invención de colores. Estas telas sacaban su valor y su precio de la vivacidad y de la resistencia de los colores. Para pintarlas se requerían unos frutos secos llamados cadou o cadoucaie en francés de las cuales se extraía el pipo y se reducían los frutos en polvo ${ }^{49}$. Las telas se pintaban de varios tonos: verdes, amarillos, naranjo clarito... y se solía dibujar flores u otras cosas. Las flores solían ser pintadas de rojo. Si se necesitaba el blanco (como solía pasar con los pistilos, las etaminas y otros trazos) se pintaba con cera. Según los enciclopedistas, también se hacían telas pintadas a imitación de las de la India que se fabricaban en Holanda y en varios lugares de Europa. Eran telas de algodón de diversos colores pero, a juicio de

\footnotetext{
${ }^{47}$ A.C.S.M., Fundación del convento de la Concepción de Santa María de Cádiz, Cuarto salida, Puerto Real, 1797. Sin catalogar.

48 Martín Carrascal Rivera y Aparicio, op. cit., págs. 94-96.

${ }^{49}$ El fruto cadou se encontraba principalmente en la zona montañosa que se extiende a lo largo de la costa de Malabar (India). Por su calidad áspera y untuosa se le atribuía la capacidad de darle resistencia a los colores. En el siglo XVIII, todavía, el fruto no tenía competencia; no se conocía otro en Europa para fijar los colores.
} 
los hombres de la época, las más bonitas eran las que venían de Persia y de la India ${ }^{50}$.

Además de las telas pintadas, sor María de la Cruz Hore compró también perlas y lentejuelas de plata fina, gusanillos brillantes y una docena y media de piedras finas de media luna. Por supuesto, estos enseres no aparecen en el inventario post mortem de la monja literata, sino en una carta escrita por su criado, letrado, localizada en el Archivo Diocesano, así como descifrando algunas notas sueltas que me entregó sor María José Odero Jaén ${ }^{51}$. Quizás, telas, velos y joyas fueron simples adornos para sor Gertrudis, alias la Hija del Sol, según la apodaron sus contemporáneos, en la (relativa) soledad de su celda, o quizás fueron asimismo señas de distinción, para que reconocieran su status aun en el propio recinto claustral.

No podemos pasar por alto el hecho de que la madre superiora estuviese al tanto de que ropa, joyas y otros aderezos entraban en la clausura. Sin embargo, en Santa María, el rigor conventual no pareció impedir algunas distracciones mundanas, tampoco el perfecto conocimiento de todo género de moda en boga durante el siglo de la Ilustración:

También es muy inoportuno al estado religioso el uso de abanico de varias modas o resaltes, que se desprenden, y desdicen de la mortaja que visten: por lo que para remediar el abuso que en esto punto se toca mandamos que ninguna religiosa tengan semejantes divisas, sino que en adelante uniformes usen abanicos bien sean blancos todos, o blancos, y negros, sin que se valgan del pretexto de que los que dejamos prohibidos se los regalen, por que si así fuere podrán aplicar estos a otros destinos ${ }^{52}$.

El uso de abanico era autorizado por el mucho calor que hacía en verano en este monasterio expuesto a las intemperies del clima y al poco socaire. A juicio de José Blanco White, era el instrumento indispensable a las españolas para poner en práctica los distintos códigos sociales utilizados por las mujeres de finales de siglo:

El abanico tiene una gran ventaja sobre el órgano natural de la conversación: es capaz de transmitir el pensamiento a larga distancia. De esta manera un

${ }^{50}$ Encyclopédie, t. XVI, págs. 370-378.

${ }^{51}$ Agradezco de todo corazón a la Reverenda Madre Sor Asunción y a mi amiga (Sor) María José Odero Jaén por su determinante labor de investigación en el archivo conventual. A.C.S.M., Las deudas conventuales de Sor María Gertrudis de la Cruz Hore. El inventario post mortem de la misma. Sin catalogar. A.D.C., Varios. Hospital de Ntra Sra del Carmen o de mujeres de Cádiz. Correspondencia particular del Magistral J. Martín Guzmán, Director administrador del hospital (1776-80), leg. 3196, s.n.

${ }^{52}$ A.D.C, Despacho de los Obispos. Fray Thomás del Valle, leg. 16, carpeta 2, f. 22. Una visita de 1771. 
buen amigo que se encuentra al otro lado del paseo es saludado cariñosamente con un rápido y trémulo golpe de abanico. Por el contrario aquel por quien se siente una completa indiferencia es despachado perentoriamente con una lenta y formal inclinación del abanico, que helará la sangre de sus venas. [...] En perfecta armonía con las facciones de las mujeres españolas, el abanico es como una especie de varita mágica cuyo poder es más fácil sentir que explicar ${ }^{53}$.

¿Podemos imaginarnos que las monjas de Santa María utilizaron estos códigos mientras se hallaban en el coro? Aparentemente, algunas religiosas no podían renunciar al deseo de ser estimadas y buscaban el honor vistiendo objetos y prendas de valor. Aquellas mujeres no hacían más que reproducir lo que ocurría fuera de la clausura: la falta de educación, la ignorancia, la falsa ambición eran defectos nacionales que se vivían con la misma cercanía en el recinto claustral.

Por ello, como subrayó Domínguez Ortiz, la historia religiosa (y aun la desdeñada historia de las mujeres en clausura) «no es sólo un simple compartimiento de la Historia sino un factor omnipresente de la vida profana» ${ }^{54}$, sólo porque la separación entre lo profano y lo sagrado seguía siendo difícil de establecer. Pero, tampoco hemos de generalizar sobre la conducta de estas mujeres. Aun en la propia comunidad gaditana tenemos constancia de seglares cuya actitud era ejemplar y de religiosas totalmente escandalizadas por tanto desorden. ${ }^{55}$ En palabras de la monja Catalina Gordillo:

Quisiera que su Santa Ilustrísima mandara que seglares, y doncellas, se vistieran, todas de uniforme por que no parece esto convento, sino que es un Rincón del siglo, pues no carecemos de estar viendo todas cuantas modas se estilan, siguiéndose aquí igualmente el lujo entre unas y otras, por que todas van a las que más pueden sobre salir ${ }^{56}$.

En la clausura de Santa María las seglares permitían a las religiosas estar perfectamente al corriente de las modas del siglo y el reto era ser la más elegante, la más atractiva, imágenes habituales en este monasterio a finales del setecientos.

${ }^{53}$ José Blanco White, «Carta Segunda. Sevilla. 1798», Cartas de España (intr. de Vicente Llorens), Madrid, Alianza editorial, 4. ${ }^{\text {a }}$ ed. 1986, págs. 72-73.

${ }^{54}$ A. Morgado García, Iglesia y sociedad en el Cádiz del siglo XVIII, págs. 7-9. (Prólogo de Domínguez Ortiz).

${ }^{55}$ Felisa de Pozo fue una de estas seglares ejemplares: el 27 de marzo de 1797, por razón de vida común, Sor Gertrudis empuñó la pluma a favor de esta mujer de setenta y tres años confirmando su residencia conventual así como su ejemplaridad y buen comportamiento al obispo. A.D.C, Fray Antonio Martínez de la Plaza, leg. 46, s.n.

${ }^{56}$ El documento no está firmado, tampoco tiene fecha, pero en la lista nominativa establecida en 1796 está atribuido a la monja Catalina Gordillo. A.D.C, Fray Antonio Martínez de la Plaza, leg. 42, f. 52. 


\section{Otras modas en boga en Santa María}

Hablar de modas en la clausura gaditana durante el siglo XVIII no es sólo hablar de la ropa o de las joyas que se llevaban, sino también de hábitos sociales. Si volvemos a leer la prensa dieciochesca, de nuevo encontramos una acerba sátira sobre la afectividad femenina; el autor del poema denuncia el uso de una moda que tuvo muchas adeptas en aquella época: el poseer animales domésticos.

Madama que la quiere y acaricia

Y cifra en ella toda su delicia

Tuvo el día pasado la humorada

De poner a Martusa engalanada,

[...] Y su qui-ri-qui-qui muy arriscado,

Periquito a la moda muy gracioso,

Con un «desmayo» atrás, pero vistoso $0^{57}$.

Según afirma Fernando R. de la Flor, parece difícil no ver en «este texto la grosera identificación entre las mujeres pendientes de las modas y los animales sin seso, disfrazados de bellas» ${ }^{58}$.

Ahora bien, si seguimos comparando esta poética reflexión con el mundo de «las santas y perfectas, / éstas que viven en los claustros» comprobamos las similitudes de costumbres que existían entre «las de fuera» y «las de dentro», opinión compartida por el propio doctor Carrascal:

A la verdad, a mí se me figuran muchas de estas Religiosas, así de ricas, como de pobres, unas bellísimas, y ajustadas seglares, con hábito de Religiosas, que tienen un pie en la clausura, y otro en el mundo [...]. ¡Ah! mejor fuera que yo me engañase; pero el dolor es, que en muchísimos Conventos de vida privada, las mismas Religiosas lo confiesan, y tal vez algunas lo sacarán al público ${ }^{59}$.

Las fuentes utilizadas en este caso son cartas de carácter privado, escritas por las propias monjas de Santa María o por sus superiores, lo cual permite adentrarnos en la intimidad de la congregación sin censura ni estorbo alguno. La decisión de establecer «vida común» (el 23 de abril de 1796) desató las lenguas, razón por la que tenemos consideraciones de interés. Las cartas revelan la pre-

\footnotetext{
${ }^{57}$ «La mona presumida», El seminario erudito y curioso de Salamanca, núm. 109 (30 de septiembre de 1794). Firmado El Cutis.

${ }^{58}$ Fernando R. DE LA FLOR, op. cit., pág. 100.

${ }^{59}$ Martín Carrascal Rivera y Aparicio, op. cit., págs. 81-82.
} 
sencia de pequeños perros en el monasterio, una presencia denunciada ya en 1785 por el obispo anterior, fray José Escalzo:

Las perrillas falderas: estos animales inútiles, y que sólo sirven para el entretenimiento, y recreo, $[. .$.$] no pueden verse sino con sentimiento en las manos que deben estar$ continuamente levantándose a Dios en la oración [...] no es posible que se tengan, y críen estos animales [...] y aunque no mandamos, que se echen, si el que no se admitan más ${ }^{60}$.

La monja Catalina Gordillo desveló a su superior el número de animales en la clausura en 1796, más de diez años tras la advertencia anterior:

Otro mandato que no se observa es el de las perritas, pues hay unas 12 o 13 en la Casa, y muchas religiosas se las llevan consigo al coro de noche, y por tener las perritas con comodidad se sientan indecentes en la presencia de Jesús Sacramentado ${ }^{61}$.

Sor María Antonia Escalera, maestra de capilla, también sintió la necesidad de denunciar aquella práctica:

Las perras aunque está mandado que no las permitan en el Convento aun permanesen en el día y no pocas siendo ciertamente perjudiciales ${ }^{62}$.

Escandalizada por el comportamiento de sus semejantes aquella monja desveló, con sus propias expresiones, situaciones en clausura que aun los superiores no se atrevieron a denunciar así:

En la portería está establecido de algún tiempo aparte que desde las diez de la mañana hasta las doce se tomen mandados de tienda y al mismo tiempo concurren otras bendiciones de varias cosas de modo que más parece carnicería que portería de religiosas y como que es tanta la inmediación de los de afuera con las de adentro por más celosas que sean las porteras no son suficientes para evitar cualquiera acción ${ }^{63}$.

La moda, más allá del vestir y de las costumbres, es un sistema de referencias sociales y culturales que participó en la transformación de la sociedad

${ }^{60}$ Son las palabras del obispo en 1785. A.D.C., Fray José Escalzo, leg. 35, ff. 138-139.

${ }^{61}$ Una carta a su superior escrita por la religiosa Sor Catalina Gordillo en 1796. A.D.C, Fray Antonio Martínez de la Plaza, leg. 42, f. 52.

${ }^{62}$ Una carta escrita por la religiosa Sor María Antonia Escalera. Ibídem, f. 48.

${ }^{63}$ Son las palabras de la monja Doña María Antonia Escalera. Ibid. 
de finales del Antiguo Régimen. La moda es más que un simple capricho, es, en palabras de Françoise Borin, «compleja» ${ }^{64}$. Es la manifestación visible no sólo de una actitud de tipo económico, sino religioso (o «irreligioso» en nuestro caso) y político. Es algo profundo que rige no sólo el cuerpo de las mujeres en la clausura (o en el «siglo»), sino también sus reivindicaciones.

Aun desde la clausura, los comportamientos de estas féminas crearon en las gaditanas nuevas emociones, nuevas formas para expresarlas, porque tanto criadas como seglares desempeñaron un papel consubstancial al espacio femenino; enlazaron las sociedades de «dentro» con las de «fuera». Quizás, conscientes de su imposibilidad para afirmarse si se conformaban sólo con la regla oficial, tanto seglares como religiosas «tomaron el poder» para definirse a sí mismas a través de hábitos sociales y de la apariencia, tal como sugirió Marry E. Perry al comentar las actitudes de seglares y prostitutas de la Sevilla de la época moderna ${ }^{65}$.

Si consideramos ahora otras comunidades religiosas, en el interesante estudio de J. L Sánchez Lora sobre Mujeres, conventos y formas de la religiosidad barroca constatamos una serie de resistencias hacia el hábito por parte de las monjas del convento de Santa Clara de Morón ${ }^{66}$. Sin embargo, al final del siglo XVII prácticamente todas las amonestaciones y recomendaciones en cuanto a costumbres conventuales desaparecen para dejar lugar a los aspectos de la organización, aspectos económicos y agrarios. En palabras de Arturo Morgado, durante varios años, existió una leyenda negra de los monasterios atribuida fundamentalmente a la obra de J. Delito y Piñuela:

Dicha leyenda es hoy en día insostenible: Sánchez Lora ha constatado la total ausencia de escándalos y abusos en el convento de clarisas de Morón por medio del análisis de los libros de visitas ${ }^{67}$.

\footnotetext{
${ }^{64}$ Françoise Borin, «Arrêt sur image», Histoire des femmes en Occident. XVIe-XVIIIe siècle, t. III, (coords.) Georges Duby y Michelle Perrot, Paris, Perrin, 2002, pág. 274.

${ }^{65}$ A principios del siglo XIV las prostitutas de Sevilla vestían tocados amarillos, prendas asignadas por ley a éstas, aunque más tarde fueron utilizadas por seglares. Por ello, a finales del siglo xv y para distinguirse, las prostitutas debían llevar además un ornamento de oropel. Mary Elizabeth PERry, Ni espada rota ni mujer que trota. Mujer y desorden social en la Sevillla del Siglo de Oro, Barcelona, ed. Crítica, 1993, págs. 55-56. Tít. original: Gender and disorder in early Modern Seville, Princeton, Princeton University Press, 1990.

66 «se toquen con decencia y compostura religiosa, bajando las tocas cuanto se pueda, y que el calzado no sea arreglado y con rivetes, que tanto desdice a la perfección de su estado.» J. L. Sánchez LoRA, op. cit., pág. 161.

${ }^{67}$ A. Morgado García, «Modelos de comportamiento religioso en la España del siglo XviII. El caso del convento de concepcionistas franciscanas descalzas de Nuestra Señora de la Piedad (Cádiz)», art. cit., págs. 213-214. No obstante, el profesor estudió el «impacto» de las seglares que residían en estas comunidades. A. Morgado García, Iglesia y sociedad, pág. 175.
} 
Destacamos dos visiones totalmente opuestas de las religiosas (son las mismas para las laicas): o eran unas «buenas mujeres», humildes, reclusas y sumisas o todo lo contrario, eran perversas, sin recato alguno y aun lujuriosas como se recoge en las obras de Julio Monreal o en las del citado Piñuela ${ }^{68}$.

Antes de compartir tal dicotomía, creo que faltan numerosos matices y detalladas monografías conventuales para poder aceptar una visión maniquea de la clausura femenina en la época moderna en España: Sánchez Lora estudia una sola congregación femenina y no puede ser ley universal; es un caso concreto, al igual que mi estudio se centra en la comunidad de monjas terciarias de Cádiz perteneciente, igualmente, a la orden Franciscana ${ }^{69}$. Empero, es de suponer que otras monjas, como las de Santa María, usaron abanicos de colores, vistieron prendas y joyas de moda en el setecientos, disfrutaron de la presencia de seglares, de criadas, de esclavas, de perros y canarios, mientras otras, confrontadas a condiciones claustrales mucho más austeras, fueron realmente «ejemplares» según la moral eclesiástica. Las idas y venidas incesantes de seglares en Santa María (obreros, lavanderas, niñas, reclusión de adúlteras, etc...) no permitieron a las monjas conservar con tanta austeridad las exigencias del universo conventual como se cumplió, por ejemplo, en el monasterio de las Descalzas gaditanas: en él no moraba seglar alguna, aunque sí tenían criadas, mientras que en las órdenes de Carmelitas reformadas no se admitían a ninguna. No hemos de olvidar que, a menudo, entrar en clausura se hacía tras conocer una existencia de seglar y, frecuentemente en las comunidades calzadas de final del Antiguo Régimen, éstas seguían rodeadas de aquéllas.

Poner de relieve parte del balance de poderes entre los eclesiásticos (no siempre a su favor) y su rama femenina (decidida a afirmarse) durante el llamado siglo de las Luces en Cádiz, descubrir la insubordinación de esta comunidad (fuesen seglares, fuesen reglares) así como su firme voluntad para actuar libremente, desvela la determinación y el comportamiento de estas gaditanas poco dispuestas a acatar todas las exigencias de sus superiores.

Discurrir sobre los géneros de moda que se llevaban en el setecientos en el monasterio de Santa María permitió adentrarse más detenidamente en este apasionante universo conventual. Poseer otra mirada sobre la clausura femenina,

${ }^{68}$ En palabras de M. ${ }^{a}$ Leticia Sánchez, la vida de la religiosa suele ser recreada a partir de la atmósfera literaria (Quevedo, Tirso de Molina, Calderón pero también Barrionuevo y Pellicer). Julio MonReaL, «Votos y Rejas», La Ilustración española y americana, xxv, págs. 7-8 y xxvi, 1880, págs. 27-28. J. DeLito y Piñuela, La vida religiosa española bajo el cuarto Felipe, Madrid, 1952. Citado por M. a Leticia SÁnchez Hernández, art. cit., pág. 72 .

${ }^{69}$ Aunque desde el Concilio Vaticano II (1965) existe una polémica sobre la pertenencia o no de la orden Concepcionista a la rama franciscana. 
estudiándola no sólo a través del prisma espiritual, sino en su vertiente más cotidiana, permitiría, entre otras cosas, volver a descubrir las vivencias de parte de la población española en el setecientos así como devolver a todas las «esposas de Cristo» su verdadero y activo papel en esta «sociedad moral» tan recelosa por conservar el honor (la misma que se sirvió de estas instituciones para que los «abusos» cometidos cayeran en el más profundo olvido) ${ }^{70}$. No relegar a las religiosas de la centuria en el apartado correspondiente a las minorías, por fin, permitiría a estas instituciones femeninas recobrar su justo valor histórico: un elemento constitutivo de la sociedad española en su conjunto.

Siglas

A.C.S.M. Archivo del Convento de Santa María (de Cádiz).

A.D.C. Archivo de la Diócesis de Cádiz.

A.P.S.C. Archivo de la Parroquia de Santa Cruz (de Cádiz).

A.S.V. Archivo Secreto del Vaticano (citado por P. Antón Solé).

${ }^{70}$ Véase Frédérique Morand, «El papel de las monjas en la sociedad española del setecientos», Cuadernos de Historia Moderna, núm. 29 (2004). 